\title{
3D collagen type I matrix inhibits the antimigratory effect of doxorubicin
}

\author{
Emilie Millerot-Serrurot ${ }^{1 \dagger}$, Marie Guilbert ${ }^{1 \dagger}$, Nicolas Fourré ${ }^{2}$, Wojciech Witkowski ${ }^{1}$, Georges Said ${ }^{1}$, \\ Laurence Van Gulick', Christine Terryn ${ }^{3}$, Jean-Marie Zahm', Roselyne Garnotel', Pierre Jeannesson ${ }^{1 *}$
}

\begin{abstract}
Background: The cell microenvironment, especially extracellular matrix proteins, plays an important role in tumor cell response to chemotherapeutic drugs. The present study was designed to investigate whether this microenvironment can influence the antimigratory effect of an anthracycline drug, doxorubicin, when tumor cells are grown in a matrix of type I collagen, a three-dimensional (3D) context which simulates a natural microenvironment.
\end{abstract}

Methods: To this purpose, we studied the migratory parameters, the integrin expression, and the activation state of focal adhesion kinase (FAK) and GTPase RhoA involved in the formation of focal adhesions and cell movement. These parameters were evaluated at non toxic concentrations which did not affect HT1080 cell proliferation.

Results: We show that while doxorubicin decreased cell migration properties by $70 \%$ in conventional twodimensional (2D) culture, this effect was completely abolished in a 3D one. Regarding the impact of doxorubicin on the focal adhesion complexes, unlike in 2D systems, the data indicated that the drug neither affected $\beta 1$ integrin expression nor the state of phosphorylation of FAK and RhoA.

Conclusion: This study suggests the lack of antiinvasive effect of doxorubicin in a 3D environment which is generally considered to better mimic the phenotypic behaviour of cells in vivo. Consistent with the previously shown resistance to the cytotoxic effect in a 3D context, our results highlight the importance of the matrix configuration on the tumor cell response to antiinvasive drugs.

\section{Background}

Cancer metastases are particularly challenging for the medical field and represent a major hurdle in cancer chemotherapy of solid neoplasia. This process confers poor prognosis for the affected patient. In fact, it is generally considered that $90 \%$ of human cancer deaths can be attributed to local invasion and/or distant metastases [1]. Given the fact that most current chemotherapeutic protocols aim at direct inhibition of tumor cell growth, the development of antimetastatic agents could be an effective means to prevent colonization, thereby enabling the containment of primary tumors in a chemically manageable form [2]. In the search of antitumor agents with anti-invasive properties, evidence has

\footnotetext{
* Correspondence: pierre.jeannesson@univ-reims.fr

+ Contributed equally

'UMR CNRS/URCA n’6237, UFR Pharmacie, 51 rue Cognacq-Jay, 51096 Reims Cedex, France

Full list of author information is available at the end of the article
}

recently accumulated indicating that anthracyclines, one of the most potent classes of chemotherapeutic agents in clinical use, inhibit tumor cell invasion [3]. Indeed, doxorubicin $[4,5]$ and related compounds such as aclacinomycin [6], or DA-125, a doxorubicin analogue [7], have been shown to inhibit in vitro invasion of various tumor cell lines originating from solid tumors when used at low concentrations. The underlying mechanism deals with either downregulation of matrix metalloproteinases [7] or disorganization of cytoskeleton and focal contacts [8].

One of the limitations of such studies is that they were performed on conventional tissue culture substrate, a situation that does not take into account the tumor cell microenvironment in which tumor cells in vivo exert complex interactions with their immediate neighbors and the extracellular matrix (ECM). For this reason, it is of primary importance in the search of cell invasion inhibitors to consider the tumor cell
C Biomed Central

C 2010 Millerot-Serrurot et al; licensee BioMed Central Ltd. This is an Open Access article distributed under the terms of the Creative Commons Attribution License (http://creativecommons.org/licenses/by/2.0), which permits unrestricted use, distribution, and reproduction in any medium, provided the original work is properly cited. 
microenvironment in in vitro drug screening regimens. Indeed, it has been demonstrated as a key determinant of cell response to anticancer drugs; this, being due to multiple mechanisms including limited drug penetration, tumor cell adaptation to hypoxia, presence of an acidic extracellular $\mathrm{pH}$ and direct contact between cancer cells and the extracellular matrix or adjacent cells that induce cell-mediated adhesion resistance [9]. In vivo, such environmental causes have been suspected to contribute to cancer cell survival after initial therapy, allowing resistant cells to proliferate.

To evaluate the impact of microenvironment on the drug response, different types of matrices have been studied such as classical two-dimensional (2D) matrices or more recently fibroblast-derived threedimensional (3D) matrices [10,11]. Studies have mainly focused on the cytotoxic or proapoptotic effects induced by an extensive panel of well-known chemotherapeutics either microtubule-disturbing agents such as vinca-alcaloids, taxoids or DNA-damaging compounds such as nitrogen mustards and anthracyclines [12,13]. It has been shown that epithelial and leukemic cell lines when grown onto such matrices may respond differently to these drugs and in some cases acquire cell mediated-adhesion resistance [10]. In accordance to this, we recently reported such a microenvironment-dependent resistance for the anti-invasive effect of anthracyclines. Indeed by contrast to plastic, human fibrosarcoma cells cultured on 2D surfaces coated with ECM proteins collagen type I and fibronectin were not affected by the antimigratory effect of doxorubicin [4]. Compared to evaluation of drug responsiveness of cells cultured on 2D coatings or onto $3 \mathrm{D}$ matrices, culturing cells within $3 \mathrm{D}$ matrices offers both a more realistic view due to the coupling of chemical and mechanical signals that takes place in the real tissues and better simulates cell response to antitumor drugs [14]. Since ECM appears as an important regulator of tumor cell response to chemotherapeutics and since nothing is known about the anti-invasive effects of anthracyclines in a 3D context, this study was designed to investigate whether the cell microenvironment can influence the antimigratory effect of the anti-tumor drug doxorubicin when human fibrosarcoma HT1080 cells are grown in a 3D collagen type I matrix. To this purpose, the current study examined migratory parameters by time-lapse videomicroscopy, the actin cytoskeleton organisation and the integrin expression. The activation state of FAK [15] and GTPase RhoA [16], two proteins involved in the formation of focal adhesion complexes and cell movement were also investigated. The data show that this $3 \mathrm{D}$ context protects the tumor cells against the antimigratory effect of non cytotoxic doses of doxorubicin.

\section{Results}

Determination of doxorubicin subtoxic concentrations in 3D cultures

To rule out a putative direct cytotoxic impact of the drug on cell migration, the ability of doxorubicin to decrease tumor cell motility was investigated at concentrations exhibiting no or limited effect on tumor cell proliferation. To this end, the effect of increasing concentrations of doxorubicin (up to $10 \mathrm{nM}$ ) on HT1080 cell growth was determined on cells either cultured in $3 \mathrm{D}$ collagen type I matrices or cultured on $2 \mathrm{D}$ plastic substrata. Figure 1 indicates that doxorubicin at 2.5 and $5 \mathrm{nM}$ inhibited 3D cell proliferation by less than $10 \%$ when compared with the control. By contrast, for 7.5 and $10 \mathrm{nM}$, cells experienced a significant increase in antiproliferative effect by $28 \%$ and $43 \%$, respectively. On 2D plastic, although more marked growth inhibitory effects were observed for the same drug concentrations, this inhibition remained limited for 2.5 and $5 \mathrm{nM}$ which inhibited cell growth by 12 and $25 \%$ respectively. For both types of culture, cell viability was not affected. Taking into account these results, the impact of doxorubicin on $3 \mathrm{D}$ cell migration was studied in all further experiments at concentrations of 2.5 and $5 \mathrm{nM}$, which did not significantly influence cell proliferation, and at $7.5 \mathrm{nM}$ as representative of a moderate cytostatic effect.

\section{Evaluation of the antimigratory effect of doxorubicin in 3D}

The migration ability of HT1080 cells cultured within collagen type I matrices has been determined by quantifying their migration speed and their 3D trajectories using computer-assisted videomicroscopy. To this end,

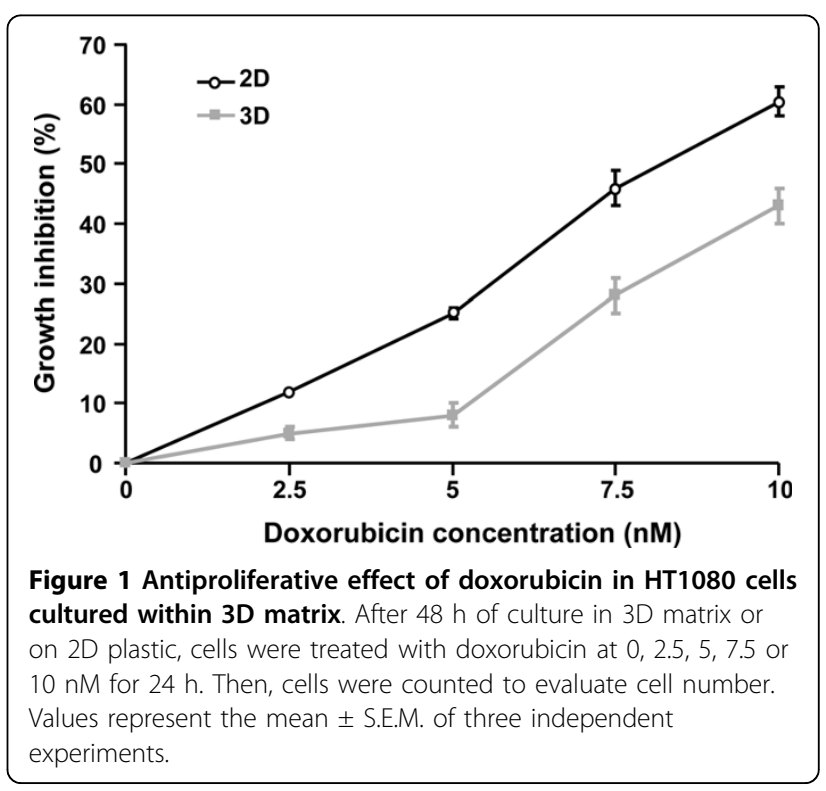


HT1080 cells were incubated with doxorubicin and individual cells were examined for their migrating potential between $12 \mathrm{~h}$ and $24 \mathrm{~h}$ after incubation with the drug. As previously shown on 2D plastic [4], doxorubicin induced a significant antimigratory effect at the non cytotoxic doses of 2.5 and $5 \mathrm{nM}$ (Figure 2). Indeed, treated cells exhibited a median speed of $5 \mu \mathrm{m} / \mathrm{h}$ compared to $18 \mu \mathrm{m} / \mathrm{h}$ in control cells, indicating that the drug inhibited cell migration by about $70 \%$. By contrast, for the same drug concentrations, the 3D collagen type I matrix totally abolished this drug antimigratory effect since the median speed of treated cells $(23 \mu \mathrm{m} / \mathrm{h})$ is similar to that of control cells $(25 \mu \mathrm{m} / \mathrm{h})$. This $3 \mathrm{D}$ collagen protective effect was also observed for the low cytostatic concentration of $7.5 \mathrm{nM}$. In addition to the estimation of the migration speed, continuous single cell tracking permitted the investigation of trajectories of cells grown in both models and treated or not with doxorubicin $5 \mathrm{nM}$ (Figure 3). In 2D, whereas control cells moved along linear paths, treated cells exhibited circular trajectories around their starting point, in accordance with cell migration speed inhibition. By contrast, in 3D, the trajectories of treated cells appeared similar to that of control cells, which is in agreement with the protective effect of collagen on cell migration speed. Taken together, our data indicate that the $3 \mathrm{D}$ collagen type I matrix protects tumor cells against the antimigratory effect of doxorubicin.

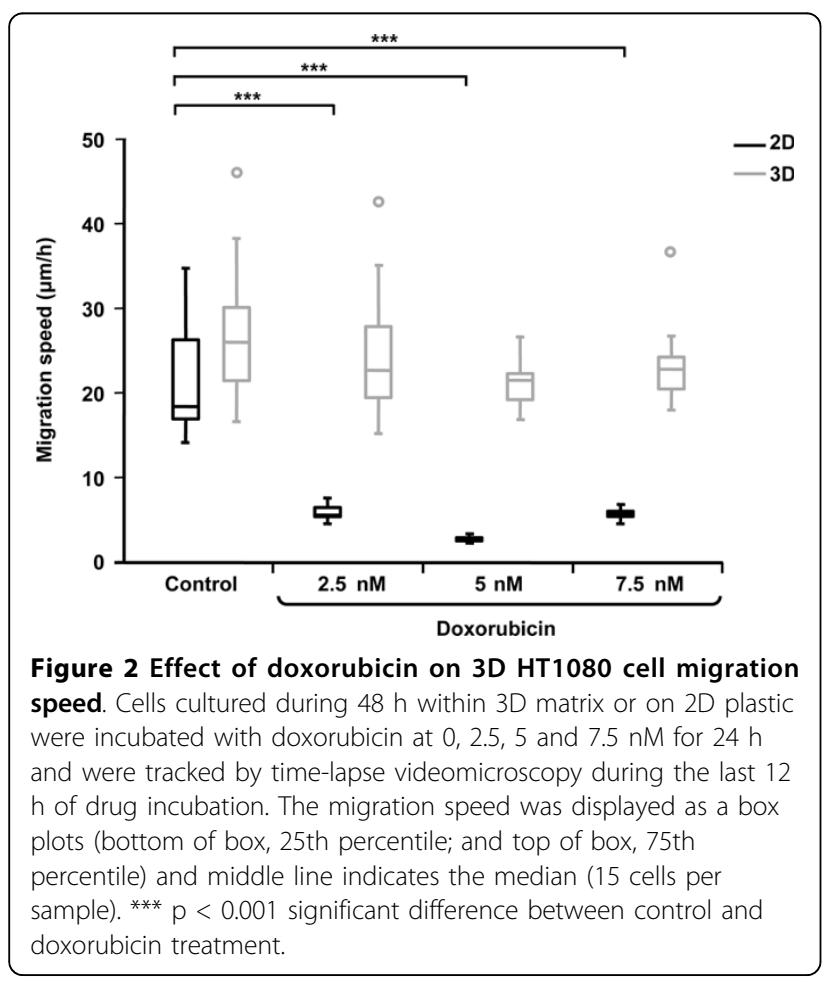

\section{Cell phenotype in 3D and impact of doxorubicin}

Inside the cell matrix, HT1080 cells adopted a morphology dramatically distinct from the one observed in cells growing on planar substrata as shown by phase contrast microscopy and localization of F-actin (Figure 4). In 2D, cells develop a flattened morphology with a classical tear-drop shape displaying a wide leading edge and a narrow tail (Figure 4A). By contrast, cells in 3D matrices demonstrate extremely elongated cell bodies with a far more compacted nucleus which can be bipolar or stellate (Figure 4B). Cylindrical branched pseudopodia structures are also observed during active phases of migration when cells explore the microenvironment to find paths between the collagen fibrils (additional files 1 and 2). Compared to $2 \mathrm{D}$, where cells exhibit a dense and regular actin stress fiber network (Figure $4 \mathrm{C}$, additional files 3 and 4), in 3D models cells show some actin bundles in the cell body continuing into pseudopodia; actin patches were also found near the cell membrane (Figure 4D, additional files 5 and 6). In addition, there was no significant difference in the total amount of actin present between $3 \mathrm{D}$ and $2 \mathrm{D}$ grown cells $(74 \pm 12$ arbitrary units/cell in 3D vs $87 \pm 11$ arbitrary units/cell in $2 \mathrm{D}, \mathrm{n}=10$ cells). In $2 \mathrm{D}$, treatment with $5 \mathrm{nM}$ doxorubicin induces a loss of cell polarity and a dramatic disorganization of the stress fibers (Figure 4E, additional files 7 and 8) whereas in 3D, cell morphology and actin distribution were similar to that of control cells (Figure 4F, additional files 9 and 10). These results clearly demonstrate that in $3 \mathrm{D}$, non toxic concentrations of doxorubicin have no effect on cytoskeleton integrity which is consistent with the collagen protective effect on cell parameters.

\section{Effect of doxorubicin on migration molecular regulators in 3D}

Since in 2D tumor cell motility is strongly dependent on the expression and functioning of integrins, FAK [15] and RhoA [16], these proteins were analyzed in 3D after drug treatment. As shown by flow cytometry (Figure 5), expression of $\beta 1$ integrins, which are representative of the integrins expressed in HT1080 cells, was found to be unaffected by doxorubicin at 2.5 and $7.5 \mathrm{nM}$ in 3D. Similar results were obtained with the same concentrations of drug in 2D culture suggesting that doxorubicin does not affect the expression level of integrins in presence or not of matrix proteins. In addition, it has to be noticed that in $3 \mathrm{D}$ culture the level of $\beta 1$ integrin expression is 3 -fold lower than in 2D culture. This decrease takes place during the first 10 hours of $3 \mathrm{D}$ culture and is in agreement with the dramatic morphological changes observed in 3D cells (Figure 6). Figure 7 depicts the western blot analysis of FAK (Figure 7A) and RhoA (Figure 7B) in $3 \mathrm{D}$ cultures treated or not 


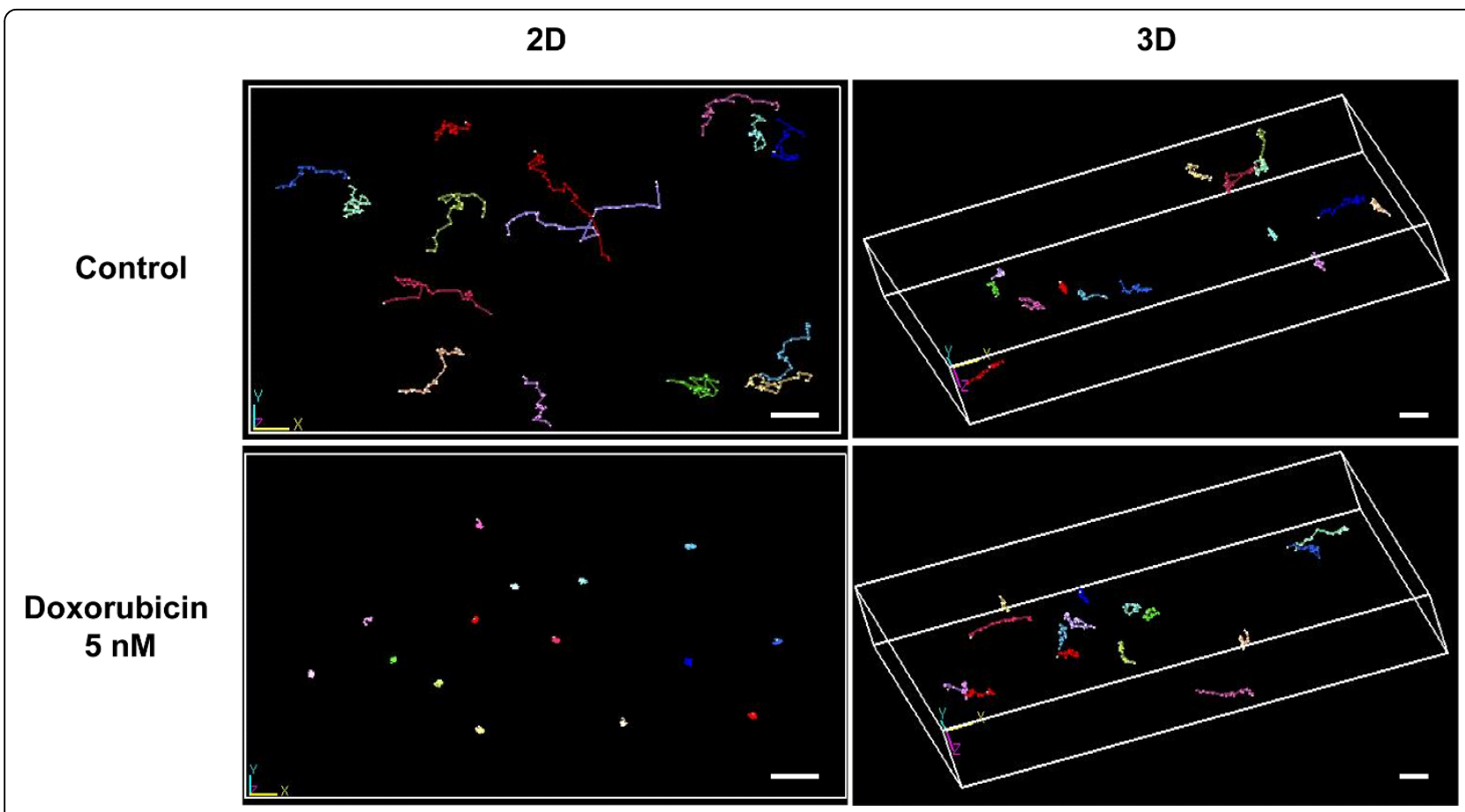

Figure 3 Quantitative analysis of 3D trajectories on doxorubicin-treated HT1080 cells. Cells cultured during $48 \mathrm{~h}$ within 3D matrix or on 2D plastic were incubated with doxorubicin 0 and $5 \mathrm{nM}$ for $24 \mathrm{~h}$ and were tracked by videomicroscopy during the last $12 \mathrm{~h}$ of drug incubation. Each colour on the figure corresponds to different cells (15 cells per sample). (Bar $=100 \mu \mathrm{m})$.

with 2.5, 5 and $7.5 \mathrm{nM}$ of doxorubicin. The data indicate that neither expression nor activation of these two proteins was influenced by the drug. These results strongly contrast with those obtained in 2D plastic cultures where the drug dramatically decreases the activation state of FAK and RhoA [4].

\section{Discussion}

We demonstrate here that 3D type I collagen matrix protects human fibrosarcoma cells against the antimigratory effect of subtoxic concentrations of the antitumor drug doxorubicin. To our knowledge, this is the first study to show that ECM proteins in a 3D configuration are able to protect cancer cells from the antimigratory effect of a drug. This protective effect can be assimilated to a new form of environment-mediated drug resistance recently described for the cytotoxic effect of various antitumor drugs [9].

The effect of doxorubicin on tumor cell migration was studied here at concentrations moderately affecting or not cell proliferation in order to exclude the possibility that its antimigratory effect could result from a non specific consequence of the cytotoxic effect of this drug. Moreover, this is of considerable interest since the use of doxorubicin is often limited by severe cardiotoxicity and other undesirable side effects [17]. The 3D culture system used here is a 3D gel of type I collagen, which corresponds to a representative model that mimicks in vivo microenvironment. Type I collagen is a main component of extracellular matrix in the body connective tissues, through which tumor cells usually move to form metastases, and use as a preintravasation microenvironment [10]. The 3D collagen gel prepared here at physiological concentration [18] approximates the 3D fibrous nature of a mesenchymal stroma by displaying a highly fibrillar organization as shown previously [19]. In addition, due to its preparation without pepsinization, this native fibrillar collagen presents intact telopeptides in contrast with most of the experimentally generated collagen matrices currently using pepsin-cleaved collagen type I [20]. Telopeptides which correspond to the flanking regions of the molecules permit to form intra- and intermolecular cross-links that promote the staggering and the resilience of fibrillar collagen [21]. Such a 3D culture model has previously been shown not to affect doxorubicin penetration both in the gel and the tumor cells, indicating that the subtoxic concentrations defined in 2D can be easily transposed to 3D conditions. Indeed, by using quantitative microspectrofluorimetry, it has been shown that doxorubicin rapidly diffuses through the 3D collagen gel so that, after $1 \mathrm{~h}$ of incubation, drug concentrations are similar in the 3D matrix and the medium covering the gel. In addition, the intracellular 

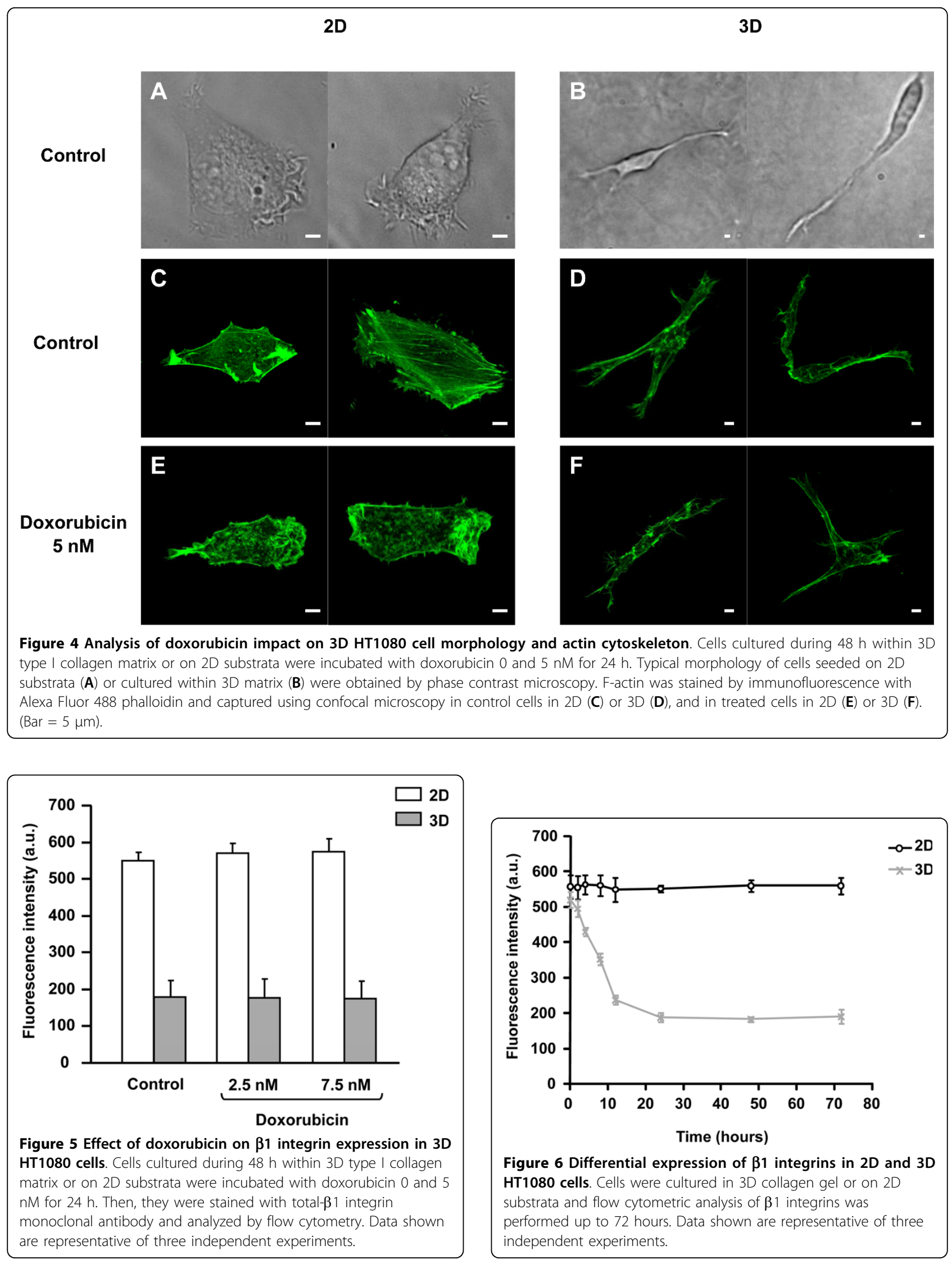
A
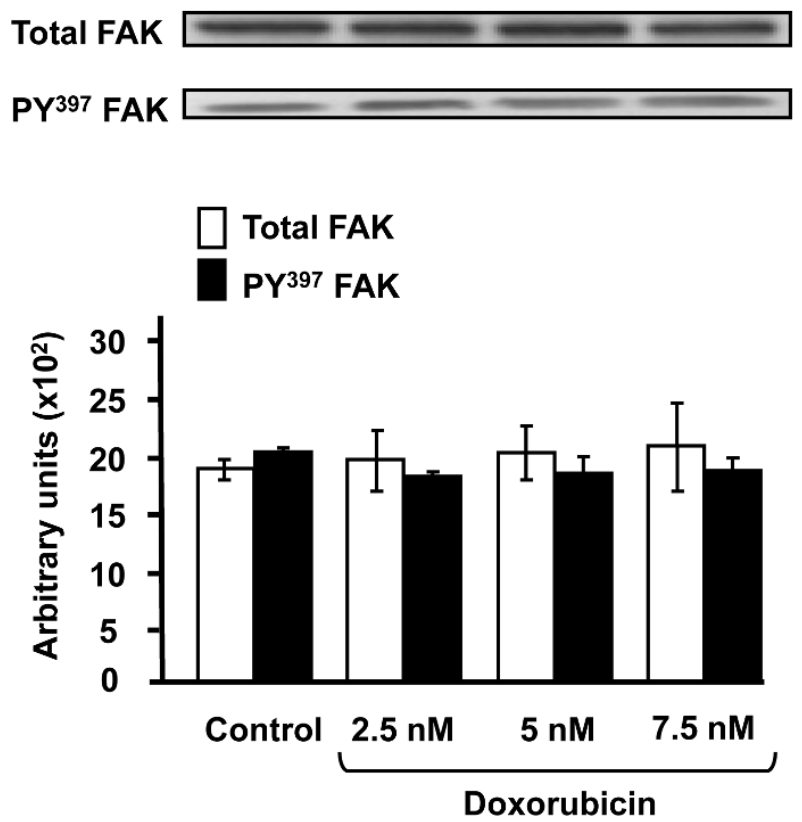

B

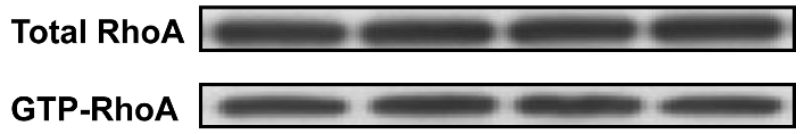

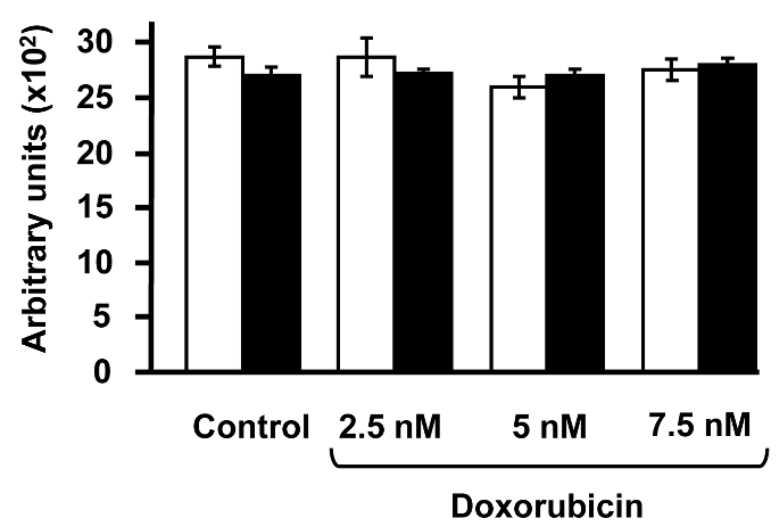

Figure 7 Effect of doxorubicin on FAK and RhoA expression in 3D HT1080 cells. Cells were cultured during 48 $\mathrm{h}$ in 3D collagen gel then treated with $2.5,5$ or $7.5 \mathrm{nM}$ of doxorubicin for $24 \mathrm{~h}$. Representative immunoblot of total FAK or Tyr ${ }^{397}$-FAK (A) and of total RhoA and RhoAGTP (B). The graphs show the mean values of three independent experiments.

penetration of doxorubicin in 3D cells is not modified compared to 2D conditions [19].

The behaviour of HT1080 cells cultured in the 3D matrices appears dramatically different from that of cells cultured on rigid and planar 2D substrata. Indeed, on 2D, cells exhibit the classical tear-drop morphology with a flat cross-section and a broad lamellipodium. On the other hand, in 3D, they adopt a bipolar, spindle or stellate shape, and express a lower level of $\beta 1$ integrins which can be explained by the marked decrease of their cell volume as estimated by flow cytometry (data not shown). The observed cell protrusions constituted of thin and cylindric dendritic extensions are in favour of a mesenchymal migration mode [22]. As recently proposed [19], and as shown in our videomicroscopy sequences, these protrusions may sense the surrounding matrix and those that extend in a favourable direction then guide cell movement. Whereas HT1080 cells migrating across 2D plastic surfaces present classical actin stress fibers, those moving through 3D collagen lack actin stress fibers but exhibit a cortical cytoskeleton and actin-rich tips in their dendritic extensions. Such structural changes are similar to those observed for human foreskin fibroblasts seeded on top of relaxed type I collagen matrices [23] and appeared to be a characteristic of the cell-collagen matrix interface. This high degree of plasticity in cell shape and actin organization may be particularly favourable during the metastasis process and may contribute to the high invasiveness potential of this cell line in animal models [24].

Cell migration speed and individual trajectories were determined using time-lapse videomicroscopy and interactive cell tracking in a four-dimensional data set [25]. It is demonstrated that cell migration speed is higher in $3 \mathrm{D}$ compared to plastic substrate $(25 \mu \mathrm{m} / \mathrm{h}$ versus 18 $\mu \mathrm{m} / \mathrm{h}, \mathrm{p}<0.01$ data not shown). In $2 \mathrm{D}$, doxorubicin markedly slows down cell locomotion by decreasing cell migration speed by about $70 \%$ and by disorganizing actin cytoskeleton. Our data are in accordance with previous studies demonstrating that other derivatives of anthracycline drugs, such as aclacinomycin [6] or DA125 [7], also exhibited a significant antimigratory effect on plastic. Surprisingly, in 3D collagen matrix, this antimigratory effect was completely abolished as proved by the absence of drug impact on cell migration speed and cytoskeleton organization. The fact that the global content of actin is roughly the same in $2 \mathrm{D}$ and $3 \mathrm{D}$ grown cells, rules out the assumption that doxorubicin has no pharmacological target (i.e., actin), thus no impact in 3D culture. Such data are completely in agreement with the inhibitory effect of ECM components on the cytotoxic mechanism of various antitumor drugs [26]. This was 
demonstrated with cell lines originating from hematopoietic or solid tumors. Indeed, these cells are protected from drug-induced apoptosis when cells were plated on ECM proteins such as fibronectin, laminin-1 and collagens [27]. In addition, our results also show that the activation of both FAK and GTPase RhoA, key regulator enzymes of cell motility, that markedly decreased in $2 \mathrm{D}$ by doxorubicin [4], is unaffected in 3D. These data are in agreement with the recent demonstration that biopsies of doxorubicin-treated breast cancer patients, exhibited upregulation of genes involved in the focal adhesion pathway [28]. In vivo, ECM proteins such as collagen type I may conceivably impair the pharmacological properties of anthracyclines, triggering an intrinsic chemotherapeutic resistance. In addition, the development of selective inhibitors of FAK is proposed as a promising way of inhibiting migration and invasion [29]; the present results provide substantial evidence that the microenvironment parameter has to be considered to isolate such inhibitors.

\section{Conclusion}

Our data clearly demonstrate that ECM proteins inhibit the antimigratory effect of the antitumor drug doxorubicin. They support the crucial role of the tumor environment in the failure of clinical response to chemotherapeutic agents and the emergence of an environment-mediated drug resistance. This experimental approach should be taken into account for a better definition of robust in vitro drug screening tests, this in order to find new agents specifically targeting the in vivo migrating behaviour of tumor cells.

\section{Methods}

\section{Cell line}

The human fibrosarcoma HT1080 cells (CCL-121) were purchased from the American Type Culture Collection (ATCC, Rockville, USA) and cultured in MEM with Earle salts and Glutamax I (Invitrogen, Cergy-Pontoise, France) supplemented with $10 \%$ fetal bovine serum (FBS) (Invitrogen). Cultures were maintained at $37^{\circ} \mathrm{C}$ in a humidified atmosphere containing $5 \%(\mathrm{v} / \mathrm{v}) \mathrm{CO}_{2}$. Cells were routinely passaged at preconfluency using $0.05 \%$ trypsin-0.53 mM EDTA (Invitrogen) and screened for the detection of mycoplasma using PCR methods.

\section{D culture and drug treatment}

Acid-extracted, non-pepsinized collagen type I from rat tail tendons was prepared as already described [30]. Lyophilized collagen was dissolved in sterile $18 \mathrm{mM}$ acetic acid at a concentration of $3 \mathrm{mg} / \mathrm{ml}$. To prepare $3 \mathrm{D}$ cultures, $5 \times 10^{4} \mathrm{HT} 1080$ cells were resuspended in $50 \mu \mathrm{L}$ FBS and mixed with a solution containing $50 \mu \mathrm{l} \mathrm{MEM}$ 10× (Sigma-Aldrich, L'Isle d'Abeau Chenes, France), 50 $\mu \mathrm{l} \mathrm{NaHCO}_{3} 0.26 \mathrm{M}, 50 \mu \mathrm{l} \mathrm{H} \mathrm{H}_{2} \mathrm{O}, 45 \mu \mathrm{l} \mathrm{NaOH} 0.1 \mathrm{M}, 5$ $\mu \mathrm{l}$ glutamine $200 \mathrm{mM}$ and $250 \mu \mathrm{l}$ collagen $3 \mathrm{mg} / \mathrm{ml}$. This solution was deposited in 24 -well plates $(500 \mu \mathrm{l} /$ well). After polymerization at $37^{\circ} \mathrm{C}$ during $10 \mathrm{~min}$, gels were recovered by $500 \mu \mathrm{l}$ MEM $10 \%$ foetal calf serum and $3 \mathrm{D}$ cultures were incubated during $48 \mathrm{~h}$ before drug treatment. Then, medium recovering $3 \mathrm{D}$ cultures was replaced by $500 \mu \mathrm{l}$ of fresh complete culture medium containing or not 2-fold concentrations of doxorubicin (TEVA Pharma S.A., Courbevoie, France). After $24 \mathrm{~h}$, gels were digested by collagenase $P$ at $1 \mathrm{mg} / \mathrm{ml}$ (Roche, Meylan, France), cell viability and cell number were determined by phase contrast microscopy. In parallel, conventional $2 \mathrm{D}$ cultures were performed by seeding HT1080 cells in 24-well plates at a concentration of $2 \times$ $10^{4}$ cells $/ \mathrm{ml}(1 \mathrm{ml} /$ well $)$. After $48 \mathrm{~h}$, culture medium was removed and cells were exposed to the doxorubicin treatment for $24 \mathrm{~h}$.

\section{D cell migration quantification and actin staining}

$3 \mathrm{D}$ and 2D cultures, prepared as described above, were seeded in 12-well plates $(2 \mathrm{ml} /$ well $)$. Cell motility was analyzed by time-lapse videomicroscopy using an inverted microscope Axiovert 200 M (Zeiss, Le Pecq, France) equipped with a small transparent environmental chamber Climabox (Zeiss) with $5 \%(\mathrm{v} / \mathrm{v}) \mathrm{CO}_{2}$ in air at $37^{\circ} \mathrm{C}$. The microscope was driven by the Metamorph software (Roper Scientific, Evry, France) and images were recorded with a charge-coupled device camera CoolsnapHQ (Roper scientific). Cell migration was quantified using an interactive tracking method as previously described [25]. For actin staining, after $24 \mathrm{~h}$ of incubation in presence of drug, cells were fixed using 4\% paraformaldehyde in PBS for $1 \mathrm{~h}$ at room temperature. Cells were permeabilized with $0.5 \%$ Triton X-100 in PBS for 5 min. Samples were blocked with PBS containing 3\% BSA with $0.3 \%$ Triton X-100 for 45 min. Factin was detected using Alexa Fluor 488 Phalloidin (1:500, Invitrogen). Fluorescence images were captured using the confocal laser scanning microscope Zeiss LSM 710 (Zeiss). The actin content of the cells was quantitated by measuring the pixel fluorescence intensity using the ImageJ software [31].

\section{Flow cytometry of $\beta 1$ integrins}

After collagenase $\mathrm{P}$ treatment of $3 \mathrm{D}$ cultures or trypsination of 2D cultures, cells were incubated at room temperature for $45 \mathrm{~min}$ with PBS containing $10 \mu \mathrm{l}$ antibodies against integrin subunits $\beta 1$ coupled with FITC (Beckman Coulter, Villepinte, France) or $50 \mu \mathrm{l}$ mouse IgG1-FITC as negative control (Beckman Coulter). Cells were then washed in PBS ( $\mathrm{pH} 7.2)$ and assessed for fluorescence in a FACSCalibur flow cytometer (BD Biosciences, Le Pont de Claix, France). 


\section{FAK activation assay}

After collagenase P treatment, cells were lyzed with extraction buffer (Tris $10 \mathrm{mM} \mathrm{pH} \mathrm{7.5,} \mathrm{NaCl} 150 \mathrm{mM}$, 1\% (v/v) Triton X-100, 5\% (v/v) PMSF $100 \mathrm{mM}, 20 \%$ (v/ v) NEM $30 \mathrm{mM}, 20 \%$ (v/v) SDS 10\%). Cell lysates were clarified by centrifugation at $10,000 \mathrm{~g}$ at $4^{\circ} \mathrm{C}$ for $10 \mathrm{~min}$. Briefly, proteins were separated by $7 \%$ SDS-PAGE gels and transferred to a PVDF membrane. Then membranes were blocked with Tris-buffered saline (TBS) $(20 \mathrm{mM}$ Tris- $\mathrm{HCl}, \mathrm{pH} 7.4,137 \mathrm{mM} \mathrm{NaCl}$ ) containing $0.1 \%$ tween (TBS-T) and 5\% non-fat dry milk at room temperature during $1 \mathrm{~h}$ and incubated overnight at $4^{\circ} \mathrm{C}$ with either rabbit polyclonal antibodies raised against total FAK (1:5000, Millipore, Saint-Quentin en Yvelines, France) or [Y397] phosphorylated-FAK (1:1000, Millipore). Membranes were washed with TBS-T and incubated with peroxidase-conjugated anti-mouse IgG (1:20000, Millipore) at room temperature during $1 \mathrm{~h}$. Chemiluminescent detection was realized by using an $\mathrm{ECL}^{+}$kit (GE Healthcare, Orsay, France).

\section{RhoA activation assay}

To assess RhoA activation, the amount of RhoA-GTP bound to the Rhotekin RBD was determined using the Rho Activation Assay Kit (Cytoskeleton, Denver, USA) according to the manufacturer's instructions. Briefly, after collagenase P treatment of 3D cultures, cells were lyzed using the lysis buffer from the kit. Proteins were incubated with RBD-rhotekin beads for $60 \mathrm{~min}$ at $4^{\circ} \mathrm{C}$. Beads were washed three times with wash buffer, resuspended in Laemmli sample buffer, and boiled for $2 \mathrm{~min}$. Separation by $12 \%$ SDS-PAGE, transfer and blocking were processed as the FAK activation assay. Proteins were immunoblotted with anti-RhoA antibodies (1:500) and chemiluminescent detection was realized by using an $\mathrm{ECL}^{+}$kit (GE Healthcare).

\section{Statistical analysis}

Data are presented as mean \pm SEM except for migration speed which displayed as box-blot ranging from the 25th to 75 th percentile including the median and whiskers from the 5th to 95th percentile. The values were analyzed with Kruskall-Wallis followed by Mann-Whitney test. Statistical significance was set at $\mathrm{p}<0.05$.

\section{Additional material}

Additional file 1: Migration of $\mathrm{HT} 1080$ cells cultured in 2D.

Additional file 2: Migration of HT1080 cells cultured within 3D collagen type I matrix.

Additional file 3: Three-dimensional visualization of actin in HT1080 cells cultured in $2 \mathrm{D}$

Additional file 4: Three-dimensional visualization of actin in HT1080 cells cultured in $2 \mathrm{D}$.
Additional file 5: Three-dimensional visualization of actin in HT1080 cells cultured within 3D collagen type I matrix.

Additional file 6: Three-dimensional visualization of actin in HT1080 cells cultured within 3D collagen type I matrix.

Additional files 7: Three-dimensional visualization of actin in HT1080 cells cultured in 2D and treated by doxorubicin $5 \mathrm{nM}$ for $24 \mathrm{~h}$.

Additional files 8: Three-dimensional visualization of actin in HT1080 cells cultured in 2D and treated by doxorubicin $5 \mathrm{nM}$ for $24 \mathrm{~h}$.

Additional files 9: Three-dimensional visualization of actin in HT1080 cells cultured within 3D collagen type I matrix and treated by doxorubicin $5 \mathrm{nM}$ for $24 \mathrm{~h}$.

Additional file 10: Three-dimensional visualization of actin in HT1080 cells cultured within 3D collagen type I matrix and treated by doxorubicin $5 \mathrm{nM}$ for $24 \mathrm{~h}$.

List of abbreviations used

2D: two-dimensional; 3D: three-dimensional; BSA: bovine serum albumin; ECM: extracellular matrix; FAK: focal adhesion kinase; FBS: fetal bovine serum; MEM: minimum essential medium; PAGE: polyacrylamide gel electrophoresis; PBS: phosphate-buffered saline; TBS: tris-buffered saline.

\section{Acknowledgements}

This study was supported by grants of Institut National du Cancer (INCa), Cancéropôle Grand-Est and FEDER/CPER. M. G. is a recipient of a doctoral fellowship from Région Champagne-Ardenne and G. S. from Cancéropôle Grand-Est. We thank Sylvie Ricord for linguistic assistance.

\section{Author details}

'UMR CNRS/URCA n6237, UFR Pharmacie, 51 rue Cognacq-Jay, 51096 Reims Cedex, France. ${ }^{2}$ IRI - CNRS USR3078, Parc de la Haute Borne, 50 Avenue Halley, 59650 Villeneuve d'Ascq Cedex, France. ${ }^{3}$ Plateforme Imagerie Cellulaire et Tissulaire, IFR 53, 51 rue Cognacq-Jay, 51096 Reims Cedex, France. ${ }^{4}$ INSERM UMRS 903, CHU Maison Blanche, 45 rue Cognacq-Jay, 51092 Reims Cedex, France.

\section{Authors' contributions}

EMS, RG and PJ designed research. EMS, MG, NF, WW, GS performed research. LV, CT, JMZ contributed to analytic tools. EMS, MG, RG and PJ analyzed data and wrote the paper. All authors read and approved the final manuscript.

\section{Competing interests}

The authors declare that they have no competing interests.

Received: 30 April 2010 Accepted: 13 August 2010

Published: 13 August 2010

\section{References}

1. Dong F, Budhu AS, Wang XW: Translating the metastasis paradigm from scientific theory to clinical oncology. Clin Cancer Res 2009, 15(8):2588-2593.

2. Perez L, Danishefsky SJ: Chemistry and biology in search of antimetastatic agents. ACS Chem Biol 2007, 2(3):159-162.

3. Simunek T, Sterba M, Popelova O, Adamcova M, Hrdina R, GersI V: Anthracycline-induced cardiotoxicity: overview of studies examining the roles of oxidative stress and free cellular iron. Pharmacol Rep 2009, 61(1):154-171.

4. Fourre N, Millerot-Serrurot E, Garnotel R, Zahm JM, Bonnet N, Millot JM, Jeannesson P: Extracellular matrix proteins protect human HT1080 cells against the antimigratory effect of doxorubicin. Cancer Sci 2008, 99(8):1699-1705

5. Doillon CJ, Gagnon E, Paradis R, Koutsilieris M: Three-dimensional culture system as a model for studying cancer cell invasion capacity and anticancer drug sensitivity. Anticancer Res 2004, 24(4):2169-2177. 
6. Addadi-Rebbah S, Poitevin S, Fourre N, Polette M, Garnotel R, Jeannesson P: Assessment of the antiinvasive potential of the anthracycline aclacinomycin (Aclarubicin) in a human fibrosarcoma cell line. Int J Oncol 2004, 24(6):1607-1615.

7. Park HJ, Chung HJ, Min HY, Park EJ, Hong JY, Kim WB, Kim SH, Lee SK Inhibitory effect of DA-125, a new anthracyclin analog antitumor agent, on the invasion of human fibrosarcoma cells by down-regulating the matrix metalloproteinases. Biochem Pharmacol 2005, 71(1-2):21-31.

8. Repesh LA, Drake SR, Warner MC, Downing SW, Jyring R, Seftor EA, Hendrix MJ, McCarthy JB: Adriamycin-induced inhibition of melanoma cell invasion is correlated with decreases in tumor cell motility and increases in focal contact formation. Clin Exp Metastasis 1993, 11(1):91-102.

9. Meads MB, Gatenby RA, Dalton WS: Environment-mediated drug resistance: a major contributor to minimal residual disease. Nat Rev Cancer 2009, 9(9):665-674.

10. Serebriiskii I, Castello-Cros R, Lamb A, Golemis EA, Cukierman E: Fibroblastderived $3 \mathrm{D}$ matrix differentially regulates the growth and drugresponsiveness of human cancer cells. Matrix Biol 2008, 27(6):573-585.

11. Mao Y, Schwarzbauer JE: Stimulatory effects of a three-dimensional microenvironment on cell-mediated fibronectin fibrillogenesis. J Cell Sci 2005, 118(Pt 19):4427-4436.

12. Sethi T, Rintoul RC, Moore SM, Mackinnon AC, Salter D, Choo C, Chilvers ER, Dransfield I, Donnelly SC, Strieter R, et al: Extracellular matrix proteins protect small cell lung cancer cells against apoptosis: a mechanism for small cell lung cancer growth and drug resistance in vivo. Nat Med 1999, 5(6):662-668.

13. Berube M, Talbot M, Collin C, Paquet-Bouchard C, Germain L, Guerin SL, Petitclerc E: Role of the extracellular matrix proteins in the resistance of SP6.5 uveal melanoma cells toward cisplatin. Int J Oncol 2005, 26(2):405-413.

14. Griffith $L G$, Swartz MA: Capturing complex 3D tissue physiology in vitro. Nat Rev Mol Cell Biol 2006, 7(3):211-224.

15. Zhao J, Guan JL: Signal transduction by focal adhesion kinase in cancer. Cancer Metastasis Rev 2009, 28(1-2):35-49.

16. Hall A: The cytoskeleton and cancer. Cancer Metastasis Rev 2009, 28(12):5-14.

17. Minotti G, Menna P, Salvatorelli E, Cairo G, Gianni L: Anthracyclines: molecular advances and pharmacologic developments in antitumor activity and cardiotoxicity. Pharmacol Rev 2004, 56(2):185-229.

18. Ramanujan S, Pluen A, McKee TD, Brown EB, Boucher Y, Jain RK: Diffusion and convection in collagen gels: implications for transport in the tumor interstitium. Biophys J 2002, 83(3):1650-1660.

19. Fourre N, Millot JM, Garnotel R, Jeannesson P: In situ analysis of doxorubicin uptake and cytotoxicity in a 3D culture model of human HT-1080 fibrosarcoma cells. Anticancer Res 2006, 26(6B):4623-4626.

20. Sabeh F, Shimizu-Hirota R, Weiss SJ: Protease-dependent versus -independent cancer cell invasion programs: three-dimensional amoeboid movement revisited. J Cell Biol 2009, 185(1):11-19.

21. Sato K, Ebihara T, Adachi E, Kawashima S, Hattori S, Irie S: Possible involvement of aminotelopeptide in self-assembly and thermal stability of collagen I as revealed by its removal with proteases. J Biol Chem 2000, 275(33):25870-25875.

22. Van Goethem E, Poincloux R, Gauffre F, Maridonneau-Parini I, Le Cabec V: Matrix architecture dictates three-dimensional migration modes of human macrophages: differential involvement of proteases and podosome-like structures. J Immunol 184(2):1049-1061.

23. Rhee $\mathrm{S}$, Jiang $\mathrm{H}, \mathrm{Ho} \mathrm{CH}$, Grinnell $\mathrm{F}$ : Microtubule function in fibroblast spreading is modulated according to the tension state of cell-matrix interactions. Proc Natl Acad Sci USA 2007, 104(13):5425-5430.

24. Yamamoto $N$, Yang $M$, Jiang $P$, Tsuchiya $H$, Tomita $K$, Moossa AR, Hoffman RM: Real-time GFP imaging of spontaneous HT-1080 fibrosarcoma lung metastases. Clin Exp Metastasis 2003, 20(2):181-185.

25. Hazgui S, Bonnet N, Cutrona J, Nawrocki-Raby B, Polette M, Chouchane L, Birembaut P, Zahm JM: 3D culture model and computer-assisted videomicroscopy to analyze migratory behavior of noninvasive and invasive bronchial epithelial cells. Am J Physiol Cell Physiol 2005, 289(6): C1547-1552

26. Morin PJ: Drug resistance and the microenvironment: nature and nurture. Drug Resist Updat 2003, 6(4):169-172.
27. Pupa SM, Giuffre S, Castiglioni F, Bertola L, Cantu M, Bongarzone I, Baldassari P, Mortarini R, Argraves WS, Anichini A, et al: Regulation of breast cancer response to chemotherapy by fibulin-1. Cancer Res 2007, 67(9):4271-4277.

28. Lee SC, Xu X, Lim YW, lau P, Sukri N, Lim SE, Yap HL, Yeo WL, Tan P, Tan SH, et al: Chemotherapy-induced tumor gene expression changes in human breast cancers. Pharmacogenet Genomics 2009, 19(3):181-192.

29. van Nimwegen MJ, van de Water B: Focal adhesion kinase: a potential target in cancer therapy. Biochem Pharmacol 2007, 73(5):597-609.

30. Garnotel R, Rittie L, Poitevin S, Monboisse JC, Nguyen P, Potron G, Maquart FX, Randoux A, Gillery P: Human blood monocytes interact with type I collagen through alpha $\times$ beta 2 integrin (CD11 c-CD18, gp15095). J Immunol 2000, 164(11):5928-5934.

31. DesMarais V, Ichetovkin I, Condeelis J, Hitchcock-DeGregori SE: Spatial regulation of actin dynamics: a tropomyosin-free, actin-rich compartment at the leading edge. J Cell Sci 2002, 115(Pt 23):4649-4660.

doi:10.1186/1475-2867-10-26

Cite this article as: Millerot-Serrurot et al:: 3D collagen type I matrix inhibits the antimigratory effect of doxorubicin. Cancer Cell International 2010 10:26

\section{Submit your next manuscript to BioMed Central and take full advantage of:}

- Convenient online submission

- Thorough peer review

- No space constraints or color figure charges

- Immediate publication on acceptance

- Inclusion in PubMed, CAS, Scopus and Google Scholar

- Research which is freely available for redistribution 